\title{
Role of protease-activated receptor-2 in inflammation, and its possible implications as a putative mediator of periodontitis
}

\author{
M Holzhausen/*, LC Spolidorio*, N Vergnolle ${ }^{+++}$
}

Department of Pharmacology and Therapeutics, Faculty of Medicine, University of Calgary, Calgary, 3330 Hospital Drive, NW Calgary, T2N 4N1, Alberta, Canada *Departamento de Periodontologia e Patologia Oral, Escola Dental de Araraquara, Universidade Estadual de São Paulo, Araraquara, SP, Brasil

Proteinase-activated receptor-2 (PAR $)$ belongs to a novel subfamily of G-protein-coupled receptors with seventransmembrane domains. This receptor is widely distributed throughout the body and seems to be importantly involved in inflammatory processes. $P A R_{2}$ can be activated by serine proteases such as trypsin, mast cell tryptase, and bacterial proteases, such as gingipain produced by Porphyromonas gingivalis. This review describes the current stage of knowledge of the possible mechanisms that link PAR activation with periodontal disease, and proposes future therapeutic strategies to modulate the host response in the treatment of periodontitis.

Key words: protease-activated receptor-2 - alveolar bone loss - inflammation - host response - Porphyromonas gingivalis periodontitis

Proteinase-activated receptors (PARs) belong to a recently described family of G-protein-coupled, seven-transmembrane-domain receptors. Activation of PARs occurs through proteolytic cleavage of their N-terminal domain by proteinases, resulting in the generation of a new $\mathrm{N}$ terminal "tethered ligand", which can autoactivate the receptor function (see Figs 1A, B) (Ossovskaya \& Bunnett 2004). Four members of the PAR family have been cloned. $\mathrm{PAR}_{1}, \mathrm{PAR}_{3}$, and $\mathrm{PAR}_{4}$ can be activated by thrombin, and $\mathrm{PAR}_{2}$ can be activated by trypsin, mast cell tryptase, neutrophil proteinase 3, tissue factor/factor VIIa/factor $\mathrm{Xa}$, membrane-tethered serine proteinase-1, or proteases from Porphyromonas gingivalis (Fig. 2) (Vergnolle et al. 2001, Lourbakos et al. 2001).

Selective synthetic peptides, corresponding to the tethered ligand sequences, are able to activate selectively the receptors through direct binding to the body of the receptor (Fig. 1C), without the need of proteolysis (Cocks $\&$ Moffatt 2000). With the exception of PAR 3 , all the other receptors have their selective agonist peptides. $\mathrm{PAR}_{1}$, $\mathrm{PAR}_{2}$, and $\mathrm{PAR}_{4}$ can be non-enzimatically and selectively activated by TFLLR-NH ${ }_{2}$, SLIGRL-NH 2 , and GYPGQV$\mathrm{NH}_{2}$, respectively (Ossovskaya \& Bunnett 2004).

In spite of showing similar structures and common mechanisms of activation, the PARs have different tissue localization and function. $\mathrm{PAR}_{1}$ can be found in human platelets, endothelium, epithelium, fibroblasts, myocytes, neurons, and astrocytes, and it seems to play a role in the vascular matrix deposition after injury. $\mathrm{PAR}_{3}$ and $\mathrm{PAR}_{4}$

Financial support: Capes

${ }^{+}$Corresponding author. E-mail: nvergnol@ucalgary.ca

${ }^{++} \mathrm{NV}$ is an Alberta Heritage Foundation for Medical Research Scholar and a Canadian Institute for Health Research Investigator

Received 8 November 2004

Accepted 30 December 2004 are found in platelets, endothelium, myocytes, and astrocytes, and they are thought to be involved in the thrombus formation and pulmonary embolism (Ossovskaya \& Bunnett 2004). PAR 2 is found throughout the body, especially in the epithelium, endothelium, fibroblasts, osteoblasts, neutrophils, myocytes, neurons, and astrocytes (Abraham et al. 2000, Uehara et al. 2003, Ossovskaya \& Bunnett 2004). PAR 2 seems to play critical pathophysiological roles, as it is involved in leukocyte migration, inflammation of joints, skin, and kidney and allergic inflammation of airways (Ossovskaya \& Bunnett 2004).

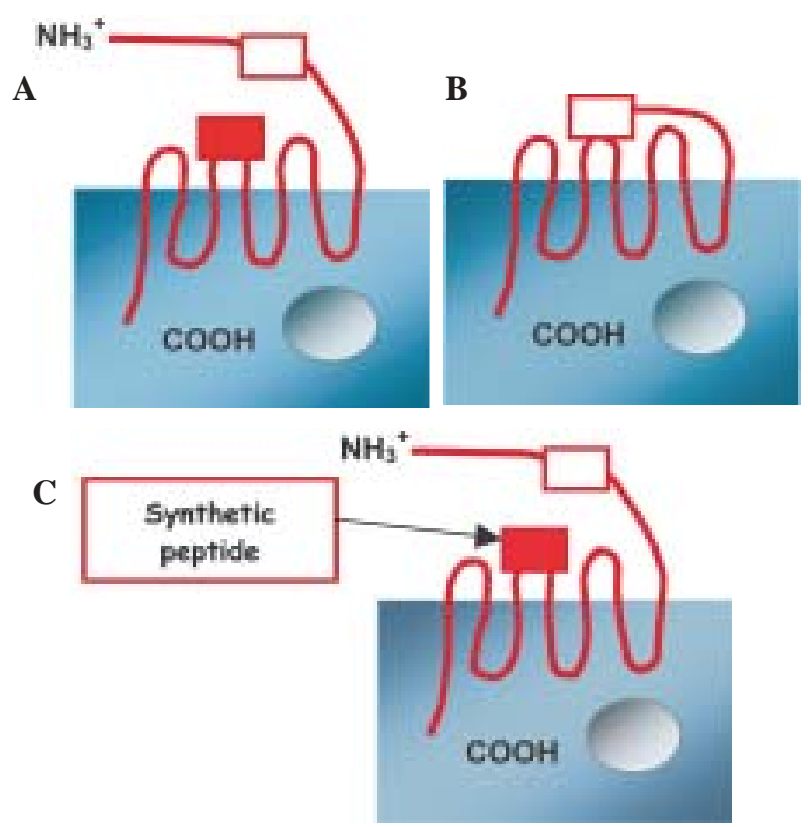

Fig. 1: mechanisms of activation of protease-activated receptor-2 $\left(\mathrm{PAR}_{2}\right)$. A represents the receptor in its "inactivated" form, waiting for the cleavage of its N-terminal domain at a specific site (besides the white box). The "tethered ligand" sequence (white box), which is exposed following enzyme-specific cleavage, binds to a site on the receptor (A and B). Synthetic peptides can also activate $\mathrm{PAR}_{2}$ by binding to the receptor (red box) without enzymatic cleavage of the receptor (C). 


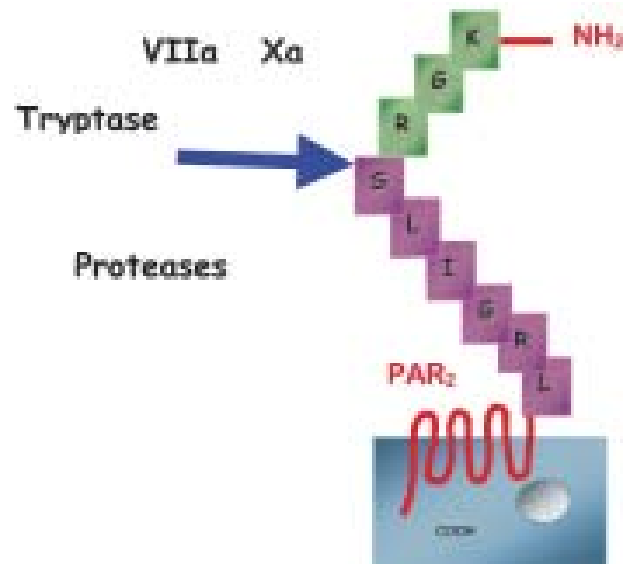

Fig. 2: enzymatic activation mechanism of $\mathrm{PAR}_{2}$. Endogenous proteases such as trypsin, tryptase, coagulation factors VIIa and Xa, and bacterial proteases, including the Porphyromonas gingivalis protease gingipain, enzymatically cleave the $\mathrm{N}$-terminal sequence of $\mathrm{PAR}_{2}$, a seven-transmembrane-type receptor, at a specific site (blue arrow).

\section{$\mathrm{PAR}_{\mathbf{2}}$ and inflammation}

The involvement of $\mathrm{PAR}_{2}$ in inflammation is supported by several studies. Early studies reported that $\mathrm{PAR}_{2}$ expression was up-regulated by inflammatory mediators such as tumour necrosis factor $\alpha$, interleukin $1 \alpha$ and lipopolysaccharide (Nystedt et al. 1996). Furthermore, deletion of $\mathrm{PAR}_{2}$ also diminishes inflammation in the airway and joints (Schmidlin et al. 2002, Ferrell et al. 2003), and delays the onset of inflammation (Lindner et al. 2000). Moreover, a number of studies have demonstrated that activation of $\mathrm{PAR}_{2}$ can lead to blood vessel relaxation, hypotension, increased vascular permeability, granulocyte infiltration, leukocyte adhesion and margination, and pain (Cocks \& Moffatt 2000, Vergnolle et al. 2001, Coughlin \& Camerer 2003), all effects that encounter for the cardinal signs of inflammation. $\mathrm{PAR}_{2}$ activation also leads to the release of prostanoids and cytokines including interleukin IL-6 and IL-8 in epithelial or non-epithelial cells (Lourbakos et al. 2001, Uehara et al. 2003). In the gastrointestinal tract, $\mathrm{PAR}_{2}$ has been localized in many different cell types: in enterocytes, in endothelial cells of the lamina propria and the submucosa, in fibroblasts, in myenteric neurons, in immune and inflammatory cells (lymphocytes, neutrophils, mast cells) (Bohm et al. 1996, Nystedt et al. 1996). Recently, we have shown that in the colon, $\mathrm{PAR}_{2}$ agonists $\left(\mathrm{PAR}_{2}\right.$-activating peptide, trypsin, tryptase) lead to an inflammatory reaction characterized by edema, granulocyte infiltration, increased intestinal permeability and proinflammatory cytokines (interleukin-1, TNF- $\alpha$ ) release (Cenac et al. 2002). Recent studies also indicate an important role of $\mathrm{PAR}_{2}$ in inflammatory pain. The receptor identified on sensory afferent nerves has been associated with long-lasting thermal and mechanical hyperalgesia in the soma as well as in visceral organs (Vergnolle et al. 2001, Coelho et al. 2002).

Taken together, these studies suggest a pro-inflammatory role for $\mathrm{PAR}_{2}$ in vivo, as it may mediate responses to tissue injury. These findings suggest that $\mathrm{PAR}_{2}$ plays a crucial role in the regulation of inflammation.

\section{Role of $\mathrm{PAR}_{\mathbf{2}}$ in periodontitis}

A possible participation of $\mathrm{PAR}_{2}$ in chronic oral inflammation such as periodontitis was indirectly suggested by several studies. First, gingipain, a bacterial proteinase produced by $P$. gingivalis, a major causative agent of adult periodontitis, was reported to activate $\mathrm{PAR}_{2}$ (Lourbakos et al. 2001). In addition, $\mathrm{PAR}_{2}$ expression was found in osteoblasts, oral epithelial cells, and human gingival fibroblasts (Abraham et al. 2000, Lourbakos et al. 2001, Uehara et al. 2003). Lourbakos et al. (2001) showed that in an oral epithelial cell line, $\mathrm{PAR}_{2}$ activation by purified gingipain induced the secretion of the pro-inflammatory cytokine interleukin-6 (IL-6), which is a potent stimulator of osteoclast differentiation and bone resorption. Uehara et al. (2003) demonstrated that a synthetic PAR $_{2}$ agonist peptide activates human gingival fibroblasts to produce IL-8 and to selectively stimulate MMP activity from these cells. This particular study suggests that $\mathrm{PAR}_{2}$ activation could account for collagen destruction associated with periodontitis lesions. Most recently, a study by Chung et al. (2004), showed that $\mathrm{PAR}_{2}$ is involved in the up-regulation of human beta-defensin in human gingival epithelial cells, stimulated by the peptide agonist of $\mathrm{PAR}_{2}$, and $P$. gingivalis proteases. Thus, this study points to a possible role for $\mathrm{PAR}_{2}$ in the gingival tissues, where its activation could act as an emergency mechanism, that would constitute a first alarm in mucosal tissues, alerting for the invasion of bacterial pathogens, and organizing a primary inflammatory response.

Taken together, these studies suggest a role for $\mathrm{PAR}_{2}$ activation in inducing inflammation and bone resorption during periodontitis. However, another study by Smith et al. (2004) suggests that $\mathrm{PAR}_{2}$ activation could inhibit bone resorption. In that study, the authors showed that the selective $\mathrm{PAR}_{2}$-activating peptide SLIGRL- $\mathrm{NH}_{2}$ inhibited osteoclast differentiation, thereby acting as a potential inhibitor of bone destruction. This result, which contradicts the suggested role for $\mathrm{PAR}_{2}$ activation in bone loss, reflects the difficulties of using in vitro approaches to evaluate the role of the different mediators that are involved in periodontal diseases.

The experiments from our group (data not published) provided the first evidences for in vivo evaluation of the role of $\mathrm{PAR}_{2}$ activation in periodontitis. We showed that local application of a selective PAR $_{2}$ agonist (SLIGRL) in oral cavity of rats, causes gingival granulocyte infiltration, and periodontitis through a mechanism involving prostaglandin release and matrix metalloproteinase activation. In addition, seven days after $\mathrm{PAR}_{2}$-agonist treatment, a peak of granulocyte infiltration [measured by an increased myeloperoxydase (MPO) activity] was observed. As polymorphonuclear neutrophils represent the main source for MPO in acute inflammation, and because they constitute the frontline of the acute host inflammatory response, promoting the release of a number of inflammatory mediators that are able to stimulate osteoclasts (Dennison \& Van Dyke 1997), it can be proposed that recruited neutrophils might be responsible, at least in part, 
for the initiation of periodontitis. Therefore, our study also suggests that $\mathrm{PAR}_{2}$ agonist-induced bone loss is due, at least in part, to the induction of an acute inflammatory response. In agreement with previous in vitro studies, which supported a destructive role for PAR (Uehara $_{2}$ et al. 2000, Lourbakos et al. 2001), our in vivo approach definitively demonstrated a pro-inflammatory and bone destruction role for $\mathrm{PAR}_{2}$ activation in periodontal tissues. Proteinases, through the activation of PAR 2 , should then be added to the number of mediators implicated in periodontal diseases (Fig. 3).

Interestingly, gingipains-R ( RgpB and HRgpA) activate also the PARs, PAR 1 and PAR $_{4}$, which are expressed on the surface of platelets and are responsible for platelet aggregation (Lourbakos et al. 2001b). This mechanism may constitute the biological plausibility of the association between periodontitis and cardiovascular disease. However, no study has yet linked the role of $\mathrm{PAR}_{1}$ or $\mathrm{PAR}_{4}$ to periodontal diseases.

\section{Conclusions}

The pro-inflammatory role of $\mathrm{PAR}_{2}$ in inflammation is adequately and clearly demonstrated by several studies, which showed that $\mathrm{PAR}_{2}$ activation leads to widespread pro-inflammatory effects, including the release of pro-inflammatory cytokines, and regulation of a number of inflammatory diseases.

The association of $\mathrm{PAR}_{2}$ with the pathogenesis of periodontitis is supported by some concepts: (i) $\mathrm{PAR}_{2}$ can be activated by gingipain, a bacterial protease produced by the major periodontopathogen, $P$. gingivalis; (ii) $\mathrm{PAR}_{2}$ is expressed by cells that are actively involved in periodontal pathologies, such as oral epithelial cells, fibroblasts, and osteoblasts, and $\mathrm{PAR}_{2}$ activation in those cells leads to the production of mediators of bone resorption; (iii) $\mathrm{PAR}_{2}$ activation by a selective peptide agonist leads to gingival granulocyte infiltration, and alveolar bone loss in rats, through a mechanism involving prostaglandin release and matrix metalloproteinase activation.

These findings indicate that $\mathrm{PAR}_{2}$ might represent a potential target for the design of drug therapies focused on the modulation of periodontal inflammation.

\section{REFERENCES}

Abraham LA, Chinni C, Jenkins AL et al. 2000. Expression of proteinase-activated receptor-2 by osteoblasts. Bone 26: $7-$ 14.

Bohm SK, Kong W, Bromme D, Smeekens SP, Anderson DC, Connolly A, Kahn M, Nelken NA, Coughlin SR, Payan DG, Bunnett NW 1996. Molecular cloning, expression and potential functions of the human proteinase-activated receptor-2. Biochem J 314: 1009-1016.

Cenac N, Coelho A, Nguyen C, Compton S, Andrade-Gordon P, MacNaughton WK, Wallace JL, Hollenberg MD, Bunnett NW, Garcia-Villar R, Bueno L, Vergnolle N 2002. Induction of intestinal inflammation in mouse by activation of Proteinase-Activated Receptor-2. Am J Pathol 161: 19031915.

Chung WO, Hansen SR, Rao D, Dale BA 2004. Protease-activated receptor signaling increases epithelial antimicrobial peptide expression. J Immunol 173: 5165-5170.

Cocks TM, Moffatt JD 2000. Proteinase-activated receptors: sentries for inflammation? TIPS 21: 103-108.

Coelho A, Vergnolle N, Guiard B, Fioramonti J, Bueno L 2002. Proteinases and proteinase-activated receptor 2: a possible role to promote visceral hyperalgesia. Gastroenterology 122: 1035-1047.

Coughlin SR, Camerer E 2003. Participation in inflammation. $J$ Clin Invest 111: 25-27.

Dennison DK, Van Dyke TE 1997. The acute inflammatory response and the role of phagocytic cells in periodontal health and disease. Periodontology 2000 14: 54-78.

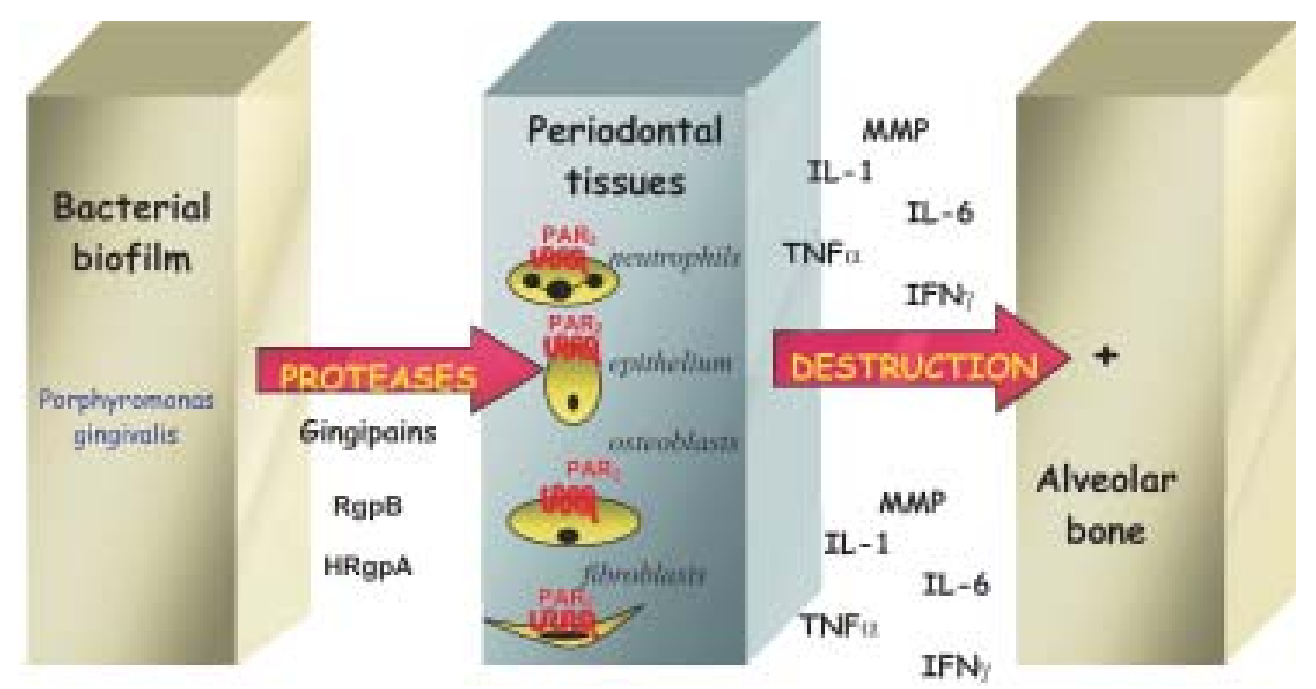

Fig. 3: possible participation of $\mathrm{PAR}_{2}$ in periodontitis. Gingipains produced by Porphyromonas gingivalis, a major causative agent of adult periodontitis, can activate $\mathrm{PAR}_{2}$ on neutrophils, oral epithelial cells, osteoblasts, and gingival fibroblasts leading to the production of a number of pro-inflammatory mediators (interleukin-1: IL-1, interleukin-6: IL-6, tumor necrosis factor-alpha: TNF $\alpha$, interferon-gama: IFN $\gamma$, matrix metalloproteases: MMPs) able to cause periodontal breakdown. 
Ferrell WR, Lockhart JC, Kelso EB, Dunning L, Plevin R, Meek SE, Smith AJ, Hunter GD, McLean JS, McGarry F et al. 2003. Essential role for proteinase-activated receptor- 2 in arthritis. J Clin Invest 111: 35-41.

Lindner JR, Kahn ML, Coughlin SR, Sambrano GR, Schauble E, Bernstein D, Foy D, Hafezi-Moghadam A, Ley K 2000. Delayed onset of inflammation in protease-activated receptor-2-deficient mice. J Immunol 165: 6504-6510.

Lourbarkos A, Potemba J, Travis J et al. 2001a. Arginine-specific proteinase from Porphyromonas gingivalis activates proteinase-activated receptors on human oral epithelial cells and induces interlukin-6 secretion. Infect Immun 69: 51215130.

Lourbakos A, Yuan YP, Jenkins AL, Travis J, Andrade-Gordon P, Santulli R, Potempa J, Pike RN 2001b. Activation of protease-activated receptors by gingipains from Porphyromonas gingivalis leads to platelet aggregation: a new trait in microbial pathogenicity. Blood 97: 3790-3797.

Nystedt S, Ramakrishnan V, Sundelin J 1996. The proteinaseactivated receptor 2 is induced by inflammatory mediators in human endothelial cells. Comparison with the thrombin receptor. J Biol Chem 271: 14910-14915.

Ossovskaya VS, Bunnet NW 2004. Protease-activated recep- tors: contribution to physiology and disease. Physiol Rev 84: 579-621.

Schmidlin F, Amadesi S, Dabbagh K, Lewis DE, Knott P, Bunnett NW, Gater PR, Geppetti P, Bertrand C, Stevens ME 2002. Protease-activated receptor 2 mediates eosinophil infiltration and hyperreactivity in allergic inflammation of the airway. J Immunol 169: 5315-5321.

Smith R, Ransjo M, Tatarczuch L et al. 2004. Activation of proteinase-activated receptor-2 leads to inhibition of osteoclast differentiation. J Bone Miner Res 19: 507-516.

Uehara A, Muramoto K, Takada H, Sugawara S 2003. Neutrophil serine proteinases activate human nonepithelial cells to produce inflammatory cytokines through proteinase-activated receptor 2. J Immunology 170: 5690-5696.

Vergnolle N, Wallace JL, Bunnett NW, Hollemberg MD 2001. Proteinase-activated receptors in inflammation, neuronal signaling and pain. TIPS 22: 146-152.

Vergnolle N, Bunnett NW, Sharkey KA, Brussee V, Compton S, Grady E, Cirino G, Gerard N, Basbaum A, AndradeGordon P, Hollenberg MD, Wallace JL 2001. Proteinaseactivated receptor-2 and hyperalgesia: a novel pain pathway. Nat Med 7: 821-826. 